\title{
Beyond the typewriter: Crowdsourcing as a case study for digital screenwriting techniques
}

John Finnegan, Falmouth University

\begin{abstract}
Research has shown how the practice of screenwriting has always been affected by technological shifts. These moments in history both mirror the current state of digital screen production and provide a rationale for debating the twenty-first-century changes in screenwriting practices. The origin of the screenplay form is linked to the evolution of the cinema apparatus and though many sectors of cinema have benefited from a migration into the digital realm, the field of screenwriting practice has been slow to follow. In Screenwriting in a Digital Era (2014), Kathryn Millard draws parallels between the screenplay and other forms of visual storytelling and describes screenwriting as a multimodal craft. Changing production practices combined with recent shifts in independent film production demonstrated how screenwriters incorporate new and unconventional methods of communicating what Ian W. MacDonald refers to as the 'screen idea' into their work. 'Kickstarter' fundraising campaigns, as one example, is one such method of communicating the screen idea through multi modal methods. An analysis of these campaigns reveals a surprising lack of attention given to the screenplay, instead relying on social media blurbs, visual pitch trailers, conceptual artwork and a multitude of other media. This paper will present a case study based on a short film, Still Life (Mac Coille, 2014), that used a crowdfunding campaign in its production, which included a combination of the screenplay and visual aids, such as conceptual artwork and a pitch trailer. The thesis of this article will
\end{abstract}


be further bolstered by other examples that support the hypothesis that future screenwriting practices will include these new technologies and methods as a mainstay. 


\section{Keywords}

screenwriting

film

'Kickstarter'

practice-led research

digital

history 


\section{Introduction}

There is a growing trend in the mainstream film industry of screenwriters adopting dual roles in productions, but also of other practitioners acting as screenwriters. In Jason Bourne (Greengrass, 2016), director Paul Greengrass collaborated with his long-time editor Christopher Rouse to write the film, while Rouse maintained his duties as film editor also. A similar method of development was used in the films of Ben Wheatley, where screenwriter Amy Jump also doubled as the editor for films such as A Field in England (Wheatley, 2013), High Rise (Wheatley, 2015) and Free Fire (Wheatley, 2016). Rogue One: A Star Wars Story (Edwards, 2016) credits screenwriters Tony Gilroy and Chris Weitz, but it gives a 'story by' credit to John Knoll, the co-production designer of the Star Wars: The Force Awakens, and the visual effects supervisor on this film. It is unusual to hear of visual effects supervisors and production designers adopting such roles, but given the fundamental role that these practitioners play in Hollywood blockbusters, such as the Star Wars franchise, there is arguably a place for them at the story development table. This would be a dramatic revision of how screenplays are developed in the industry. It is one that is owed in part to the technological advancements of the industry, such as readily available post production tools and camera equipment.

In researching the relationship between such advancements in technology and the craft of screenwriting, it is necessary to give consideration to the industrial origins of the screenplay text. A historical analysis of the craft of screenwriting can further support claims that the writer exhibits an enhanced role in the production of a film, and reveals much about why many screenplay 'rules' and conventions exist in a multi-departmental development system. In such productions, the script is accompanied by directors, cast, source material and conceptual artwork to help in the elaboration of the project. Yet, outside of this model, the 
screenplay is often the only source for what Ian W. MacDonald refers to as the 'screen idea' (2013). In an alternative mode of production, the suitability of the screenplay as a vector to communicate the screen idea alone, can be re-examined, with the aim of suggesting other methods instead.

Research into alternative methods of writing for the screen, such as Millard's Screenwriting in a Digital Era (2014), suggests that the practice of screenwriting has entered an age where an abundance of accessible media can offer new approaches to the adaptation from script to screen, no longer bound by the traditions of old (2014: 180). Screenwriting Scholarship has also become a widely accepted field of study in its own right and not simply an offshoot of traditional film studies. This bridging of cultures in both academia and industry can be seen in the recommended reading section of the Nicholl's Screenwriting Fellowship site, which features an extensive list of screenwriting manuals, and also several key academic texts. This demonstrates the value and contributions of academic research into screenwriting, which are now being felt at the highest levels of the screenwriting communities ('Screenwriting Resources' n.d.). Innovations in new media technologies, such as flash animation, graphic design programs and high-definition cameras found in a multitude of gadgets ranging from smartphones to handheld video game consoles, has meant that the opportunities for practitioners in the visual arts are numerous.

In From the Theory and Practice of a Script Writer, the Russian formalist Osip Brik argues that the script is in no way a literary work, but that it is 'a system of cinematic images and devices calculated to make the author or authors' artistic project open out on the screen in the forms of cinematic art' (1974: 96). Though dismissive of the screenplay's status as a literary artefact, he is supportive of the scripts potential to take other forms, besides the written word. 
The fact that we do not have any means other than words with which to plan the future film is in no sense intrinsic to the script; rather, it is a defect. In some cases, an expressive photograph can give a fuller idea of the future than long pages of flowery literary script. Scripts are written for the people who will be making the film. An understanding of the film envisaged has to be conveyed to them by all the means available, and for this purpose, literary language is far from the only or the most appropriate means (Brik 1974: 96).

The changing production practices mentioned previously, combined with recent shifts in independent film production, demonstrate that the written word is no longer the only means by which screenwriters can communicate their screen idea to practitioners. 'Kickstarter' fundraising campaigns serve as a contemporary example of Brik's argument. What makes the 'Kickstarter' campaign so interesting from a research perspective is the little attention the screenplay text is given in their creation. An investigation into many successful campaigns suggests that the traditional screenplay is unnecessary in the fundraising process. These campaigns instead rely on social media blurbs, visual pitch trailers, conceptual artwork and a multitude of other media to convey and communicate the screen idea. This is one example of the way in which screenwriting has become a multimodal craft, a method of screenwriting which employs, not just written texts, but images and sound also (Millard 2014: 180). This can now afford the screenwriter a more diverse toolkit of resources to outline their story.

In this article, I will highlight a relationship between the logistical aspects of a film's production cycle and the screenwriting process, and will demonstrate that in fact the screenwriter has always been impacted by changing production trends and models in the film industry. It will begin with an explorative study of the history of screenwriting as a craft, looking specifically at the relationship between the media and technology of the time, and the 
influence it played on the craft of screenwriting. As Azlant argues, 'it is fitting to pursue the origins of the screenplay through film's evolving complexities of materials, features, schemes, and through the backgrounds, attitudes, and activities of the artists attending this evolution' (1997: 228). To this end, I will demonstrate that the development of such production technologies is directly linked to the formalization and standardization of the screenplay, but that this evolution is continuing to shape and revise the standards of screenwriting.

The article will explore screenwriting and its relationship to new media, looking at the different modes and tools available to the practitioner, but also explore the various avenues of development that these new tools can afford the filmmaker. This can offer new agency to the writer, and offer greater opportunities for filmmakers to develop and adapt their screenplays, where traditionally they would be hindered by restrictive and expensive filmmaking trends.

This article will make the argument that the 'Kickstarter' fundraising page, itself a new digital addition to the overall screenplay package, is just as significant as the treatment or outline. The 'Kickstarter' campaign represents a convergence of digital culture that theorists like Henry Jenkins speak of, and traditional film practices that have changed the nature of screenwriting, and unsettled it from its positions both in scholarship and in the eyes of the wider film community. An industrial case study will support this argument, a short film called Still Life (Mac Coille, 2014), which was written and developed as part of this research. The film was written as a speculative screenplay and produced using funding that was raised through an 'Indiegogo' crowdfunding campaign. The campaign employed many of the same tools that have already been described, making it an ideal case study for demonstrating the ways that screenwriters can now employ alternative tools to the written word, as well as other technologies, such as social media and video, in the development and communication of the screen idea. 


\section{The long-standing relationship between media and screenwriting}

This section looks at the ways in which the screenplay has evolved since the late nineteenth and early twentieth centuries and explores its relationship to the technology that surrounds it within the wider film industry. It will begin by addressing the formalization of the screenplay in the early studio system of Hollywood and also broaches unorthodox approaches to the craft, particularly the influences of other media in screenwriting from that period. Research into this period can help disclose some of the underlying motivations of the screenplay's form, particularly its connection to other media. More significantly, it can provide a foundation from which scholars can study the relationship between screenwriting and technology in a contemporary industry. The section concludes with a look at how changing production practices in the industry influenced the way in which we now perceive the screenplay within screenwriting culture.

In exploring the evolution of the craft of screenwriting, it is useful to begin with the etymology of the term 'screenplay'. As Maras explains, the term 'screen play', an earlier derivative of the word, also refers to the film as a 'visual performed object, or exhibited entity, much like its earlier counterpart term "photoplay"' (2009: 82).

The screen play did not simply or instantaneously switch from being a performed and filmed object to a written one. The appropriate conditions needed to arise for a shift in textuality from image to word to happen. Some of these are linked to changing understandings of the art of the photoplay [...]; others relate to credit practices and institutional politics (Maras 2009: 83).

To Maras' list of influences, I would also like to add technological advancements. As the newspaper article is dependent on the printing press, so too is the screenplay bound to the 
production practices of filmmaking. To help better understand the formalization of the screenplay, it is useful to identify the technological advancements of the time that helped influence its shape. However, as scholars of screenwriting and film history remind us, it is difficult to conduct such an investigation that seeks to revisit the earliest filmmaking attempts, as many, if not all the screenplays of that earliest period of the cinema have been lost to us. Some key theorists in the field have attempted to collate what surviving works there are and present us with a clearer timeline. Price, Maras, Bordwell and Thompson, Staiger, Azlant, Loughney, Raynauld and Stempel, have all written about the origins of the classical cinema and the primitive cinema. Their research will serve as a base for the work of this section.

The cinema of that period, in the late 1800s and early 1900s, was, as Gunning terms, a 'cinema of attractions' (1986), one that was not built on narrative but on the prospect of looking. The appeal of cinema at this point was predominantly a technical one, with technological pioneers such as Thomas Edison at the helm. The camera was the main attraction for new filmmakers and the construction of a narrative was placed secondary to this new creative tool. The scenario was lacking in any formalization during this period of the 'cameraman system' (Staiger cited in Price 2013: 55), where the filmmaker was a writer, director and cinematographer, with each filmmaker adopting their own preferred methods of writing. The earliest screenwriters emerged from this media-rich culture, bringing their expertise in graphic arts and many other professions in the media to the thriving medium of cinema (Azlant 1997: 249).

In his book, A History of the Screenplay, Price refers to the 'accidental' nature of screenwriting's origins, 'stage plays and newspaper articles that were not written with films in mind' (2013: 25), but that would come to play a key role in the creation of early films. One of the earliest examples of the filmmaker explicitly borrowing from other media in the construction of their screen narrative was the Sigmund Lubin re-enactment of the Corbett- 
Fitzsimmons heavyweight boxing championship fight in 1897, where two performers were prompted by a 'director' reading from a newspaper article (Azlant 1997: 229). Further examples demonstrate how the scenario's relationship to other media of the time helped in establishing its status as a culturally recognisable text. Loughney highlights AM\&B's attempt to register the scenario for The Suburbanite (McCutcheion 1904) with The Copyright Office. 'The Copyright Office, thinking that the bulletin was not a true dramatic composition because it lacked dialogue, replied to $A M \& B$ that it would be more proper to register the work as a “book" than a play’ (Loughney 1997: 284). One of the ways in which studios bypassed this issue was to embrace existing structures of other media. Soon AM\&B's scenarios were modelled after the theatrical play (Price 2013: 50). These examples reveal that one of the biggest influences on the writer of the day was the stage play. Cases such as Salmi Morse's doomed Passion Play (1879) being adapted for the screen (Vincent 1898) with greater success, has helped foster the relationship that exists even today between the theatre and the cinema. Literary writers found it difficult to become part of this growing movement of storytellers being hired to work for production companies. Screenwriting at that time was not considered a literary craft, and understandably so. The scenario was clinical and treated as an organizational tool. To add insult to injury, the technological and multimodal aspects of the film production made it difficult for literary writers to migrate into the motion picture industry. As Price explains, the suggestions for literary based scenarios that the studios received, 'were developed in the studio into scripts, since few of the writers possessed the knowledge of picture-making requisite to enable them to develop the script' (2013: 55). The studios needed visual thinkers.

The increasing complexity of film narratives, combined with the formalization of distribution and exhibition standards meant that filmmakers had to change their approach to the craft, warranting the need for 'clearer preparation at the writing stage' (Price 2013: 56). Roy L. McCardell, one of the most interesting scenarists of this 'director-unit' system, holds 
the distinction of being the first person hired by a studio, the Biograph Company, to write specifically for the pictures (Loughney 1997: 281). Aside from being a pioneer in this growing sector of the arts, McCardell is fascinating because of his background in writing for magazines and other media. McCardell was a journalist with the Birmingham Age-Herald, The New York Evening Sun, Puck, The New York World and The New York Sunday Telegraph, while contributing poetry and prose to Pearson's, Everybody's, Harper's and Century. He was a novelist, as well as writing musicals and dramas for the stage. At The New York World, McCardell shared credit for the introduction of the first colour page comic supplement. He wrote serialized stories about everyday New York life and his impact on readers was strong, receiving outpours of letters from the public. McCardell wrote captions for his comic spreads and as renowned scenarist of the time, Epes Winthrop Sargent recalls, 'he and the boss would hire a lot of models - mostly girls - and go out and make pictures for the captions' (Azlant 1997: 231). The publications featured photo illustrations, 'often illustrating make-up or costume sequences or key scenes of current theatrical entertainments' (Azlant 1997: 231). It was this 'vital synthesis of cartoon sequencing, photography and narrative conceit' that is believed to be what attracted Biograph to recruit McCardell to write for the mutoscope (Azlant 1997: 232). His extremely high salary of 200 dollars a week led to a rush of other journalists looking to join the ranks of the film industry (Stempel 2000: 5). Though he would leave Biograph within a year, McCardell would go on to have great success writing scenarios for nearly every studio producer on a freelance basis, and during this period McCardell still maintained his interest in other media, writing plays, novels and illustrated magazine publications.

McCardell was clearly a prolific screenwriter who emerged from and maintained contact with many forms of popular media. He brought to film concrete experience in the creation of comic strips, popular Broadway musicals and comedies, newspaper 
vignettes and serials, poetry, narrative photography, and popular fiction, not to mention an awareness of the vicissitudes of writing in an institutional context like the daily newspaper. (Azlant 1997: 234)

McCardell's photo stories with captions, which were printed in magazines, resemble the storyboarding techniques of many filmmakers today, many of which involve live action previsualization techniques. The techniques that filmmakers employ to help realize or complete the screenplay text mirror the early storytelling techniques of McCardell and others of his time, and these techniques no doubt helped to refine their capacity for visual thinking, something that made them ideal for working within the visual arts. The application of their visual skills to the scenario can be credited with helping to develop diverse cinematic techniques, such as montage and editing, as well as narrative.

Ultimately the 'talkie' represented a shift to a more complex method of film production, one that required greater attention in the pre-production stage. It proved to be the catalyst that would propel the heterogeneous format of the script into a formalized mode of writing, thus distancing itself from the other forms of media that proved so influential in its initial form. Azlant suggests that the increased complexity of narrative and filmmaking techniques, combined with an ever-evolving studio system, 'helped institutionalise screenwriting' (1997: 239) and affirm its place within the wider film landscape. This also led to an arguably dangerous dependency on the script to function as a blueprint for the filmmaking process as well (Azlant 1997: 246). This shift, from story document to production blueprint occurred in the mid-to-late 1920s when Thomas Ince, an American silent film producer and director, revolutionized the film industry by adopting an assembly line approach to filmmaking and introducing what we now refer to as the producer-driven system, with the continuity script as its engine (Price 2013: 75). 
That process was planned, and the plans, which existed on paper in a variety of forms, were subjected to oversight (or interference, depending on one's point of view) by managers. A manager could be, as in Ince's case, the head of the studio, or he could be a supervisor, or production supervisor, or producer. And one of the written forms the producers used as a method of control was the written script. (Stempel 2000: 51)

According to Price, this created 'a more centralised mode of production whereby the studio maintained quality and economic control over the multi-reel 'features' that had now become the norm for narrative filmmaking' (2013: 76).

The conversion to sound resulted in a slew of formats and approaches to the writing and formatting of dialogue (Price 2013: 140). However, even as far as the 1950s no clear agreement could be made among studios as to how to universally format the screenplay, as evidenced by the scripts of the time. An analysis of two key texts of that period, Sunset Boulevard (Wilder, 1950) and On the Waterfront (Kazan, 1954), reveals a stark contrast in how these scripts are structured. 
AJs

SUISET BOULEVARD

SEQUEYTCE "A"

A-1 START the plcture with the actual street sign: SUNSE? BOULEVARD, stencilied on a curbstone. In the gutter Ise dead leaves; scraps of paper, buint matches and cigarette butts. It is early morning.

Now the CAMERA leaves the sign and MOVES EAST, the grey asphalt of the street filling the screen. As speed accelerates to around $40 \mathrm{~m} . \mathrm{p} . \mathrm{h}$., trafric demarcetions, white arrows, speed-imit warnings, manholo covers, etc., flash by. SUPTRIMPOSED on all of this are the CREDIT TITLES, in the stencilled style of the street sign。

It is a bleck County hearse. The license plate says: CALIFORNIA, 1949 -- together with a number. The metal frame around the plate is stamped with the words IOS ANGELES。

PAIN UP HIGHER. Painted across the back of the hearse is the word CORONER.

\section{DISSOLVE TO:}

THE GOROINER'S HEARSE TURITHG DOWN AN ALLEY TEADIHG IFTO THE COUITY WORGUE

It pulls up before a closed gate of steel grillwork. on the vali is a sign: SOUND HORN, The driver does so. An attendant opens the gate. The hearse passes through it and into

\section{A-3 A TUNiNEL, and then into}

\section{A SMALIL COURTYARD}

The hearse backs up to an unloading platform and again the horn is sounded. Two white-clad attend.ants come out of the morgue while the arivor and a sleepy official descend from the hearse. The attendants open the door in the back of the vehicle and wheel out a hospital cart on which lies a corpse covered with a bromish blaniret. Only the corpseis feẹt show, clad in cheap cotten socks and scuffed moccasins. They are soaking wet. PAN with the feet as the cart is wheelad into a siraly room near the entrance to the building and brought to a stop.

-DISSOLVE TO: 
FADE IN :

1 EXT-ESTABLISHING SHOT-WATERFRONT-NIGHT

Shooting toward a small building (Hoboken Yacht Club) set upon a wharf floating about twenty-five yards off shore. A long, narrow gangplank leads from the wharf to the shore, and on either side of the wharf are large ocean liners which are being unloaded by arc light. In the B.G. is the glittering New York skyline. A great liner, blazing with light, is headed down river. A ferry chugs across to Manhattan. There is a counterpoint of ships' whistles, some shrill, others hauntingly muted.

2 CLOSER SHOT-SMALL BUILDING-ON WHARE-NIGHT

It is the office of the longshoremen's local for this section of waterfront. Coming along the gangplank toward the shore is an isolated figure. He is TERRY MALLOY, a wiry, jaunty, waterfront hanger-on in his late twenties. He wears a turtleneck sweater, a windbreaker and a cap.

He whistles a familiar Irish song.

3 SERIES OF WALKING SHOTS-TERRY MALLOY-WATERFRONT-NIGHT

Reaching the shore and turning away from the union office. Passing the burned-out piers.

Turning up a waterfront tenement street lit by a dim street lamp that throws an eerie beam. He is holding something inside his jacket but we cannot see what it is.

NOTE: MAIN TITLES TO BE SUPERIMPOSED OVER THIS SERIES OF SHOTS

4 EXT-WATERFRONT STREET-NIGHT

Terry walks along until he reaches an ancient tenement where he stops, hesitates, looks up toward the top of the building, and putting his fingers to his mouth lets out a shrill, effective whistle that echoes up the quiet street. Then he cups his hands to his mouth and shouts:

\section{TERRY}

Hey Joey! Joey Doyle! 
Figure 1: Sunset Boulevard (Wilder, 1950) and On the Waterfront (Kazan, 1954).

An analysis of the screenplay form today reveals many traits and conventions whose origins can be traced back to this turbulent time where the screenplay's identity was still in question. Many of these traits are arguably outdated or unnecessary now. For example, the acknowledged font of the screenplay, twelve-point Courier, is a clear reference to the scripts of old. Kathryn Millard explains, 'the packaging of Courier with the first PCs ensured that users would be able to replicate typewriter-looking documents, enabling a smooth transition to the new era of word processing and personal computing' (2014: 34). Screenplays are generally expected to introduce character names for the first time in upper case. Perhaps this was a convention used for directors or actors to take note of important characters, but it is by no means a vital component of a script, especially considering that no work of traditional literature would conform to this same trend. The use of upper case when referring to sound effects on the page is again a tribute to editors or sound designers who quickly needed to identify audio for a scene. The notion that one page of the screenplay is equal to a minute of screen time is also one that is regularly debated by screenwriting scholars and practitioners alike, but in practical terms it is a convention that is almost impossible to adhere to, if we accept that the screenplay is a fluid document that will change on set or in editing. It appears that the screenplay has always been shaped to adhere to the technological aspects of film production. However, these strict conventions that writers are forced to follow exist to cater to a period of filmmaking that could not fathom the independent branches of cinema that would arrive later, nor the digital revolution that would revise many of the codes and practices of filmmaking today. It is an outdated method and one which Millard considers 'unsustainable' (2014: 180).

This raises the question as to whether or not the screenplay is suitable in its current form to carry the burden of all the various complexities that make up the contemporary theatrical film. What if the screenwriter, particularly the speculative writer, could better 
communicate the screen idea by embracing a wider array of multimedia in their work ethic, much like the scenarists of the early cinema years? History has shown how technological innovations have propelled the screenplay into new and uncertain states. Digital multimedia tools have presented filmmakers with a fresh way to convey their screen idea, encouraging a familiarity with various forms of media technologies, and taking emphasis away from the conventional screenplay as a means of doing so.

Today the craft of screenwriting is often separated from other departments and this has discouraged screenwriters from engaging with other aspects of production in the creation of their ideas. Many contemporary screenwriters are now wholly unfamiliar with editing techniques, or the paradigms of cinematography, due to this departmentalized production model that places such a heavy emphasis on the written word. Worse still, this lack of technical literacy exhibited by writers is deemed acceptable and the norm.

\section{Unconventional approaches to screenwriting}

In the previous section, I attempted to establish a relationship between changing filmmaking technologies, and the screenplay form, by highlighting the impact that technological advances in filmmaking had on the practice of screenwriting in the early twentieth century. I used historical examples to show the role that other media outside of cinema have played on informing not only the script itself but the writer and their process, in what was arguably one of the most creative periods for the writer in the history of the cinema. Now I will explore the screenplay in contemporary cinema, looking specifically at the extent that digital technology has further informed the screenplay's shape.

The advent of digital technology has given rise to a variety of industries, including video game design, online streaming services for film and television and a host of tools available for content creation, that employ production design documents similar to the screenplay. In theory, the term 'screenplay' can represent a production document pertaining 
to any form of visual media. The benefits of this redefinition are many, not just from a practitioner's point of view, where employment is a key concern. It also affords the scholar a broader canvas from which to conduct research, no longer limited just to the film medium. Accepting the screenplay as an open document and not bound to a single visual media can have ramifications for how we theorize the screenplay and can call into question many of the singular views that have existed for a long time within the Academy. However, in professional circles, the role of the screenplay and the writer has yet to be recognized in these sectors.

The digital tools available to the filmmaker have unwittingly changed the culture of filmmaking and naturally, screenwriting. In fact, the digital screenplay is a far more complex idea now. It does not exist in a physical form and can theoretically exist as a continuously changing draft if the writer chooses, one that is never 'final' in the strictest sense, overwriting the previous work and questioning what we consider to be a draft. The writing of the digital script requires a degree of literacy beyond that of spoken and written language. It requires a technological literacy. Screenwriting software, such as Final Draft and Celtx have gained a large following among writers due to the high-profile endorsements they received from industry insiders. While these programs remove the arduous task of formatting the page on traditional Word programs, they also foster a reliance on these tools and a culture of complacency among screenwriters who follow the codes and conventions of mainstream screenwriting without question. These programs also fail to acknowledge the potential for the screenplay in video game design, the web series, various independent avenues of cinema and television, or animation. They force a one-size-fits-all model on the writer that resembles the screenplay of old. The virtual screenplay remains as such only until it is required to become a printed and physical script again.

The independent sectors of cinema, have now become a haven for experimentation both at the production stage, but also in the pre-production stage, and in these corners of 
cinema, the screenplay has found new life. Independent cinema around the world has become a fountain of innovative practices and technological revolution. One such revolution in the American independent cinema of the early twenty-first century, was the 'mumblecore' movement, a series of ultra-low-budget films that employed minimal crew and cast and favouring a docu-drama style. Mumblecore was a movement of films that were created at a similar period of time, with stories that reflected the real lives of the people who were making them. The films are made using digital technology, in keeping with the low-budget nature of the productions and this purely digital way of making films offered a level of freedom in how the screenplay was and is still used in the production process. This natural and improvisational nature of mumblecore is of particular interest to screenwriting scholars who call into question the necessity of the screenplay in these digital movements.

One of the most interesting trends in recent independent cinema has been for filmmakers to avoid using traditional screenplays in making their films. Not only have emerging film-makers associated with the so-called 'mumblecore' movement, such as Joe Swanberg, Aaron Katz and Ronald Bronstein, veered away from depending on conventionally written screenplays, but other critically acclaimed films, including The Pool (2008) and Ballast (2008), have as well. Indeed, some of the most notable American indie film-makers - Gus Van Sant, David Lynch and Jim Jarmusch - have employed alternative strategies to the screenplay in such recent films as Elephant (2003), Inland Empire (2006) and The Limits of Control (2009). (Murphy 2010: 175)

Humpday (Shelton 2009) is another key example of how an experimental approach at a screenplay level was encouraged from the beginning of production. Director Lynn Shelton explains, 'one of the main things would be instead of trying to write a script and find people 
from a very large pool to fit that vision, to start with people you want to work with and then invite them to develop their own characters' (Guerrasio 2009).

The ultra-low-budget methods of film production are not the only avenues where experimentation with the screenplay is evident. Though quite rare, there are pockets within the mainstream industry that foster this same type of creativity in the writing process. Robert Rodriguez, who rose to fame in the independent film festival circuit with similar filmmakers such as Quentin Tarantino and John Singleton, has since become a supporter of digital technology in cinema. For the production of Sin City (Rodriguez et al. 2005). Rodriguez teamed with the author of the source graphic novel, Frank Miller, to co-direct the almostentirely digital endeavour. In order to be allowed to work with Miller, a non-unionized filmmaker, Rodriguez relinquished his Director's Guild of America membership to turn what was to become one of the most talked about Hollywood movies of the year into a somewhat independent venture. The film, which was shot entirely on a green screen stage, made significant use of the Sin City graphic novels in its production. The graphic novels were used as a reference on set, and many of the shots of the film were framed to match the panels of the page, as Rodriguez explains, 'I started really looking at it as, instead of trying to turn it into a movie, which would be terrible, let's take cinema, and try and make it into this book. Because the mediums really are very similar' (2004).

Dialogue, for the most part, was also lifted directly from the source material. The role of a traditional screenwriter was so unnecessary in the production that they intentionally chose not to acknowledge it in the opening and closing credits. This in turn inspired director Zach Snyder to make similar use of the source material for his adaptations of Frank Miller's 300 (Varley and Miller 1999) and Alan Moore's Watchmen (1986). Though Snyder's films included a traditional screenplay in both productions, they were complemented by the visual qualities of the source material in the adaptation from page to screen. 
These examples of what Maras refers to as 'scripting' (2009: 129), a term he privileges over the narrow 'screenplay', offer a departure from the traditional method that has dominated film practice for so long. What each of these represents is an embracing of technology and media in the development of visual art, thus encouraging filmmakers to become equally innovative in the development of the story. Given the success of these particular examples, it is easy to dismiss the screenplay in favour of these other tools, however, these examples prove that the role of the screenplay in the early development is still vital to the process, if only as a document to outline the various steps of the film's production. It is the form of the script that is being called into question here, the traditional form that writers have become so familiar with. The form that filmmakers such as Rodriguez and Snyder embrace here is a literal mode of writing for the screen, using visual tools not only to convey a sense of the screen idea but to allow us to visualize this idea with the appropriate visual vocabulary in a way befitting the medium of cinema. In recalling the early days of Roy L. McCardle, and the other pioneers of the screenwriting profession, the scholar can now draw comparisons between the past and the present. In the same way the term 'screen play' once referred to the visual artefact and not the page, so too now is the 'screenplay' becoming a visual document in its own right. The line between writer and filmmaker is fading as the tools and techniques of both professions converge towards each other.

\section{Crowdsourcing as a digital vector for the screen idea}

In this section, I will discuss how crowdfunding platforms such as 'Kickstarter' and 'Indiegogo' have helped foster such a convergence of writer and filmmaker. The crowdfunding campaign serves as a new method of engaging with and communicating the screen idea to audiences, using a host of different media tools and services. In many respects, 
the crowdfunding page has become an equally valid production document and represents a shift in how practitioners engage in the screenwriting process in a digital realm.

In recent years crowdfunding has become a popular method of raising funds for various types of projects, particularly those in the creative arts. The most successful platform is 'Kickstarter'. In the independent film communities crowdfunding has become one of the key sources of securing financial support, with many films having a better chance of going into production than if they followed the traditional route of seeking funding from a national film organization such as the BFI or the Irish Film Board, or by seeking investment from mainstream film producers.

'Kickstarter' has also been used as a vehicle by mainstream artists as a way of proving marketplace value for an otherwise struggling Hollywood project, or to work outside of the restrictive Hollywood system. In April 2013, Rob Thomas launched a 'Kickstarter' campaign to fund a feature film adaptation of the cancelled television series Veronica Mars (2014). The campaign was a huge success, raising $\$ 5.7$ million from a total of 91,585 backers around the world (Dredge 2014). Actor and filmmaker Zach Braff similarly raised \$3.1 million in 2013 to develop feature film Wish I Was Here (2014), as did Spike Lee and others (see Dredge 2014). Such high-profile projects have helped these platforms establish a new means of film development.

What makes the 'Kickstarter' campaign page fascinating, from a screenwriting perspective, is the lack of a screenplay in support of it. An analysis of these pages shows that the only reference to the screenplay in both cases is as a reward for backers who support the project. 


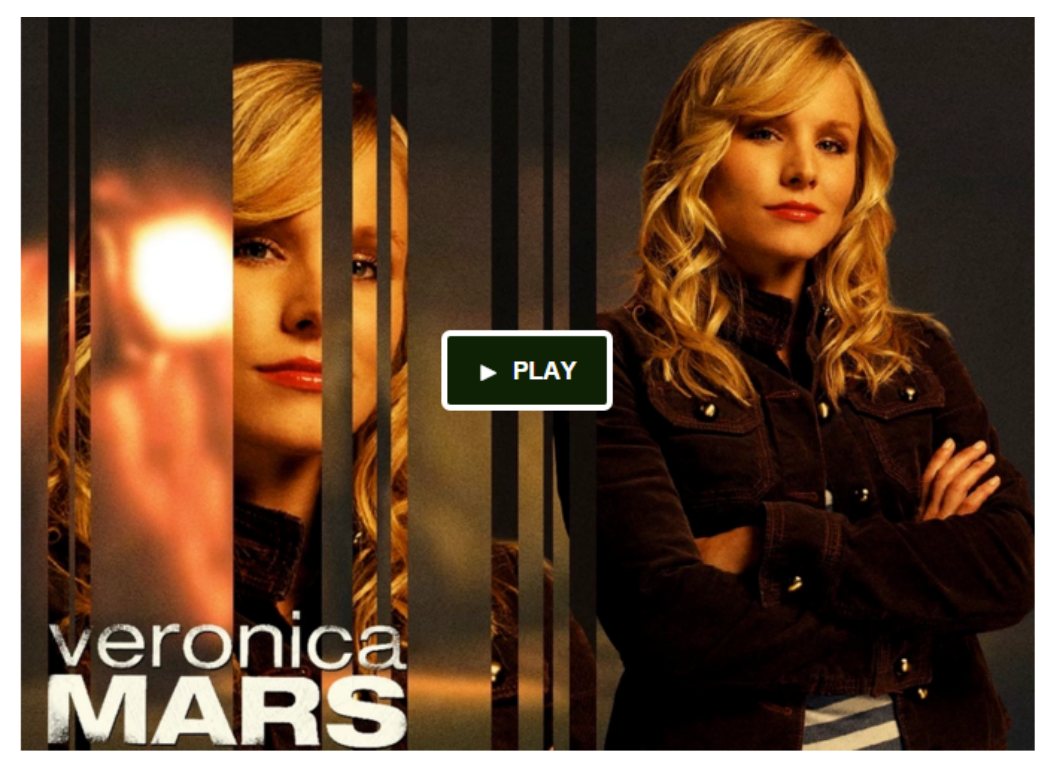

San Diego, CA Narrative Film
$\$ 5,702,153$

pledged of $\$ 2,000,000$ goal
Pledge $\$ 1$ or more

- 5,938 backers

Don't have much to spend, but want to help the cause? At \$1, you'll still have our eternal gratitude, plus you'll receive exclusive backer updates throughout the production! Help us become the biggest Kickstarter project yet. (Please.)

Estimated delivery: Apr 2013

\section{Pledge $\$ 10$ or more}

- 8,423 backers

You'll be sent a pdf of the shooting script on the day of the movie's release. Read it or remain unspoiled, the choice is yours. Additionally, you will receive regular updates and behind-the-scenes scoop throughout the fundraising and movie making process.

Estimated delivery

Feb 2014

Figure 4: The Veronica Mars movie screenplay offered as a reward to backers on their 'Kickstarter' page.

This is a considerable departure from the traditional funding routes, where a screenplay is a key document in the deciding of what gets funded and what does not. In fact, in conventional funding models, the script is often the only document considered when getting passed the initial gatekeepers of the industry.

It can appear that typical scripting documentation does not play a role in crowdfunding, however, I would argue a revision is needed for what nowadays we consider to be a typical production document. The crowdfunding page employs visual materials, including YouTube videos (primarily used as pitch trailers), conceptual artwork, character biographies and casting materials, as well as a toolkit that accommodates the web page as a platform for communicating what is essentially a strictly visual and audible concept. These visual materials are a form of adaptation, in that they take the text-based script, and adapt it for the Web 2.0 consumer base. This method of communicating the screen idea is an appropriate example of how the craft of screenwriting has caught up with the innovations of film production practices of the twenty-first century. 


\section{Case study: Still Life}

In this section, I will demonstrate the development of a crowdfunding campaign page from a screenwriting perspective. The crowdfunding page was for a live action short film Still Life, based on a screenplay that I wrote. As a producer on the film, I was also heavily involved in the development of the campaign page which was made on 'Indiegogo' (which, unlike 'Kickstarter', allows the artist to retain a percentage of any funding they earn, whether or not they have achieved their goals). As the screenwriter of the film, I saw the 'Indiegogo' campaign as an opportunity to pitch the story of the film to a wide audience, by employing various multimedia that appeal to the consumption habits of media consumers today. The campaign page then resembled a variety of screenwriting documentation, in that it contained a synopsis, excerpts from the script, cast and crew biographies, as well as character breakdowns and a visual pitch trailer that attempted to break down the story and the rationale behind the production.

Still Life follows a young woman, Olivia, who works tirelessly to care for her father who is suffering from dementia. The film was written in 2013 as a speculative screenplay, and in 2014 it was acquired and put into production by an Irish production team. We chose to crowdfund the production for several reasons, most notably because of the freedom it offers filmmakers who are not bound by the agendas of investors. Our film would not be treated as a commodity or held to any standards outside our own vision. Another reason we chose this was due to the limited and arguably restrictive modes of financing that are available to filmmakers within filmmaking institutions. In Ireland, the main source of film funding comes from the Irish Film Board, a government-funded agency for supporting the film arts. However, the Irish Film Board functions like any other film finance organization, in that it too has an agenda and seeks to oversee the project so that it falls in line with its own standards of practice. This is not a negative issue and it is acknowledged to be part of any venture where significant financial investment is involved. But in the case of crowdfunding, 
the filmmaker has a level of freedom to operate that they do not get under other more conventional financing arrangements.

An appropriate YouTube video at the beginning of the page is a cornerstone of any crowdfunding campaign and in this campaign, the visual pitch trailer was seen as a first impression and a test of our ability to operate at a professional level. As the video is the first section of the page, it was important that it convey all the key points of information that we needed, indeed a summary of the overall project. As screenwriter, I took it upon myself to write the short script for the video from the point of view of the film's lead actor, Ruth Hayes, and edit the narration into a series of still imagery and video, to create a compelling introduction to the project and to highlight the importance of the story we were trying to tell. Some of the imagery was created or edited in Photoshop, while some were drawn from personal family albums. I also drew from footage from previous projects, as well as work from other members of our crew. 

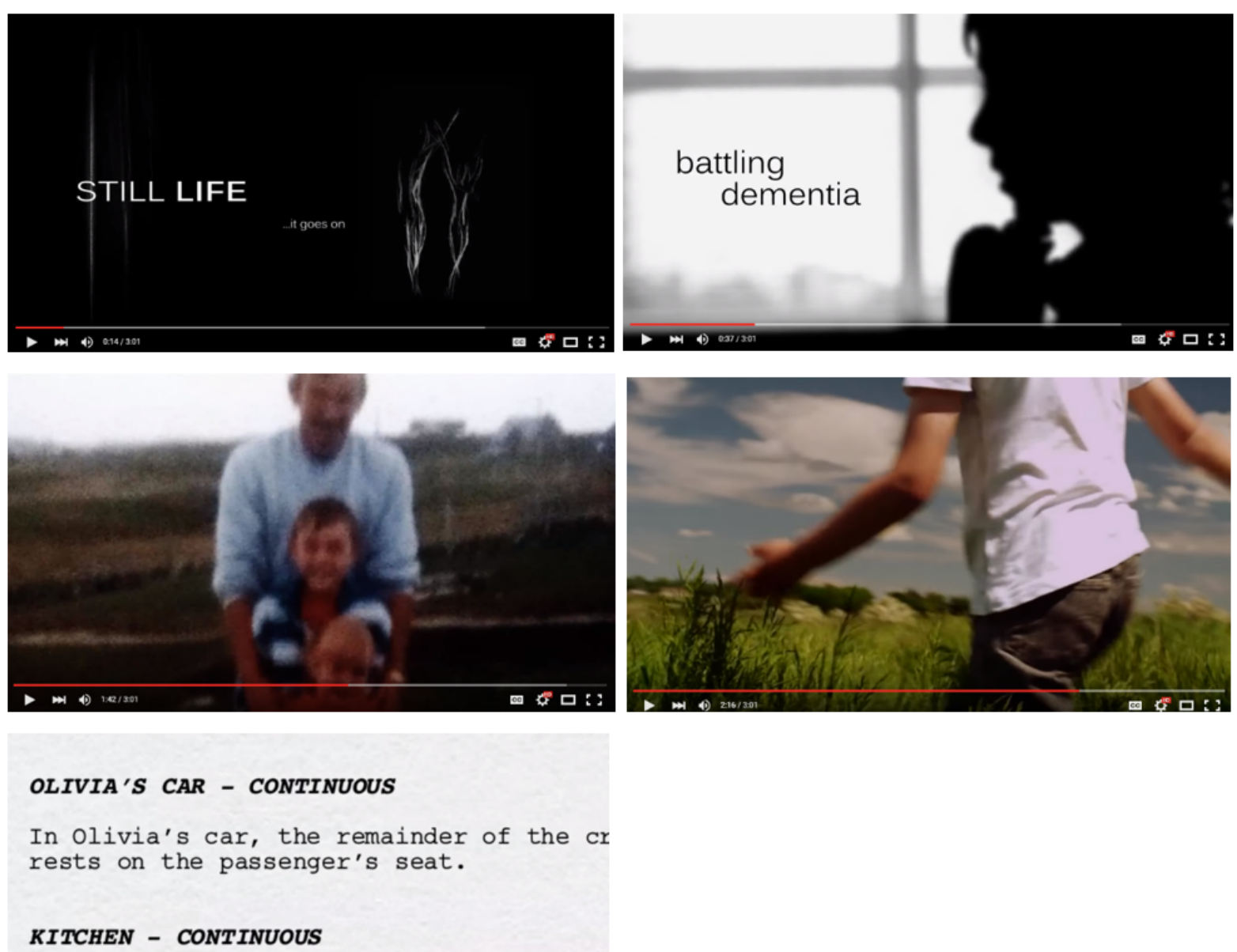

Figure 5: Screen captures of the Still Life promotional video on 'Indiegogo'.

The video also gave us a chance to create a compelling logo and title sequence. The end result was a piece of visual art that used nostalgia and audience identification as a narrative device in order to draw the viewer in to read more about the film.

The final sections offered short biographies of the cast and crew of the film, to demonstrate our experience to date, and the level of professionalism and commitment to quality that we were bringing to the production. Finally, we included a brief explanation of how 'Indiegogo' works (to help those who were unfamiliar with the process of crowdfunding) and gave links to our social media pages on Twitter and Facebook so that our backers could continue to engage with us throughout the production. 
The most notable trait of this campaign was the minimal presence of the screenplay. The issue of screenplay literacy played a factor in my choice not to include the full script in the campaign, as many potential backers might not understand how to read a script or understand the visual language employed. They might not understand the conventions of screenwriting, such as 'INT.' or 'EXT.', or any of the other medium-specific codes of screenplay jargon. Rather than including the entire twelve-page screenplay on the campaign, an excerpt was posted on my blog Please Return to the Script Dept. (Finnegan 2014) and hyperlinked to the campaign.

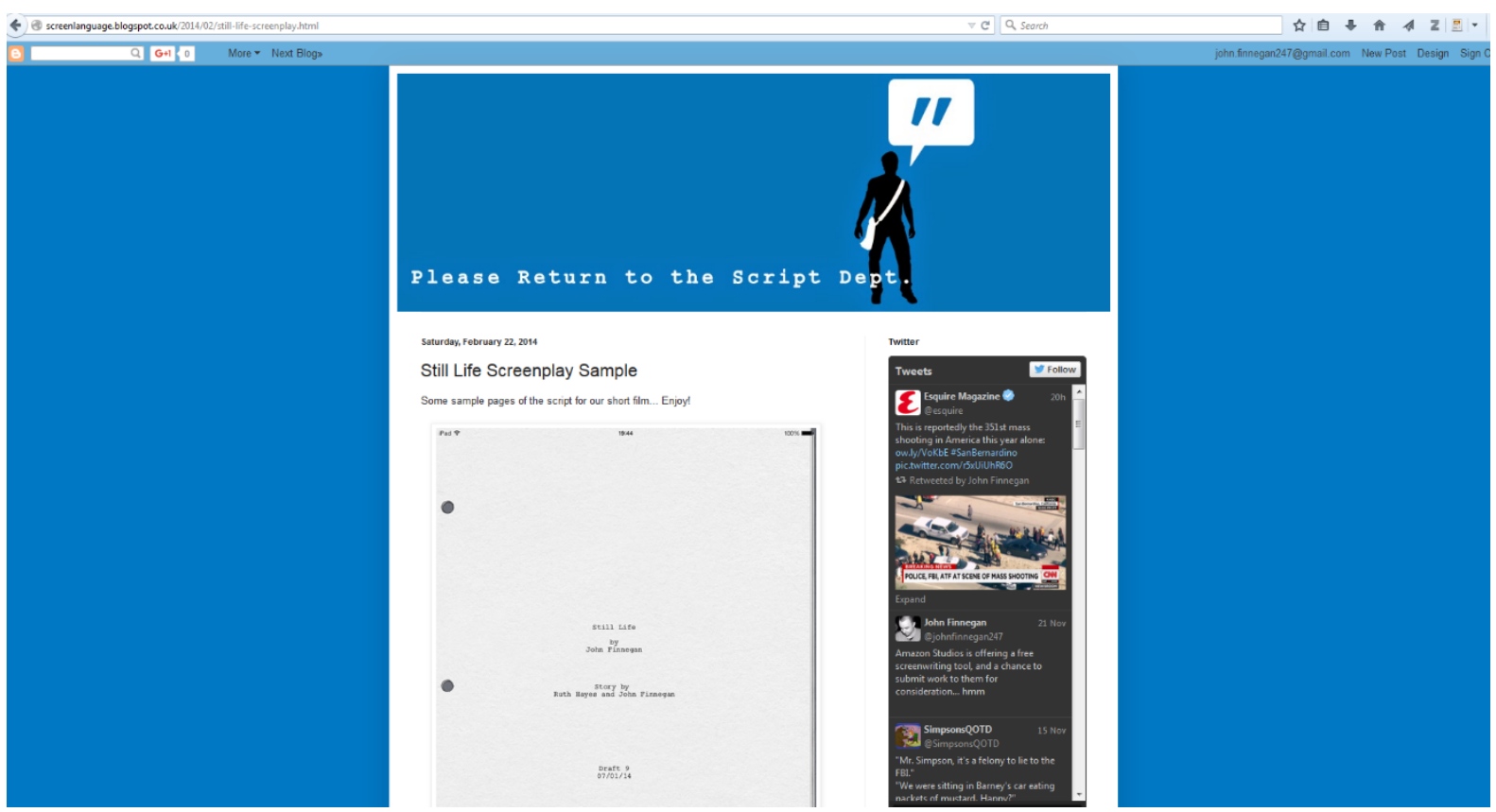

Figure 6: Script excerpts on my blog.

The research benefit of having the screenplay on my blog, rather than on the campaign page, was that I could monitor traffic to the script posts, and gauge how significant a role the traditional script played in the campaign. This was achieved using Google Blogger's analytical tools that are included with the blog service. 


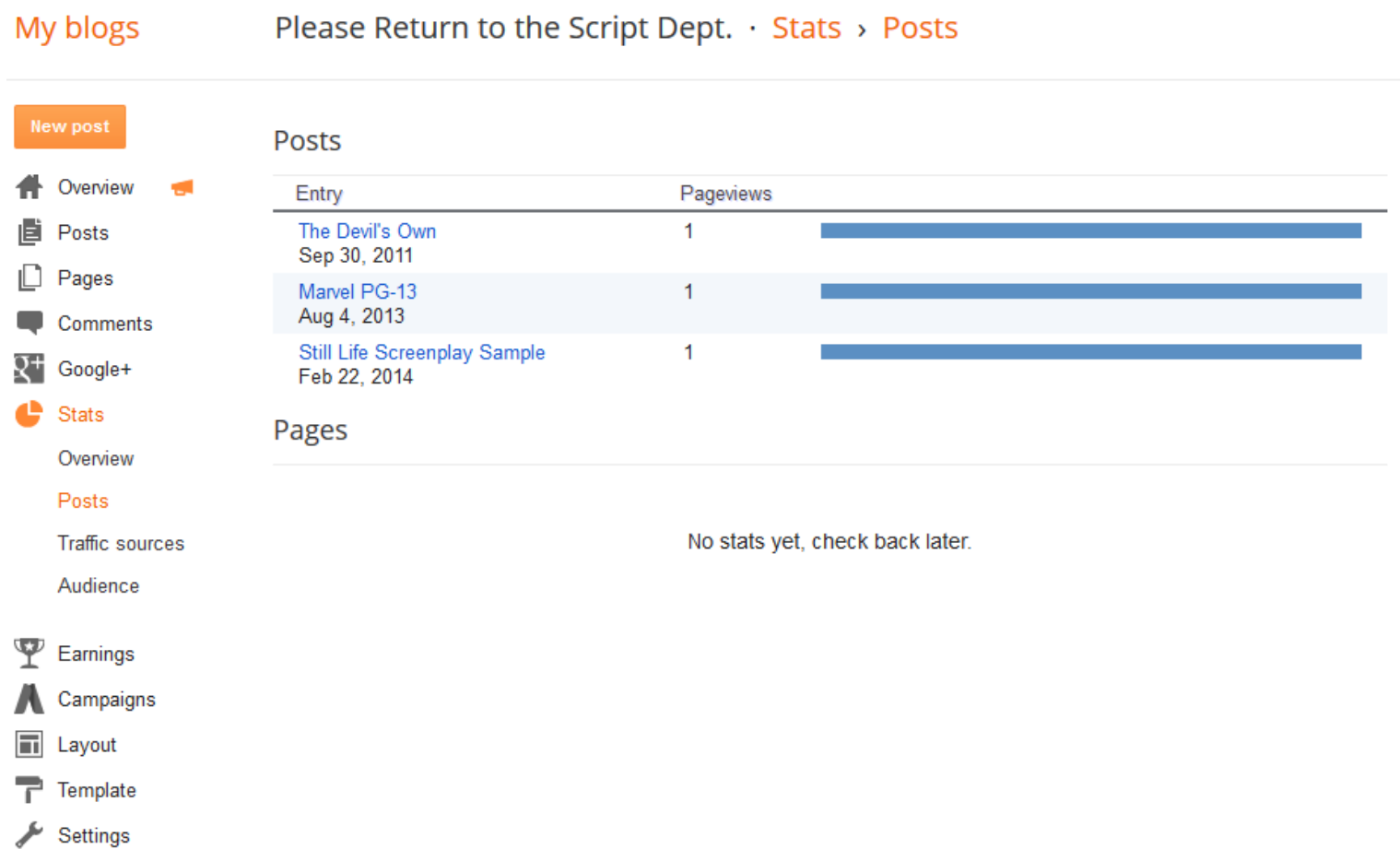

Figure 7: Pageviews for screenplay excerpts.

The results showed that only one person viewed the screenplay excerpts, thus confirming my initial hypothesis that the script had little impact on the overall success or failure of a 'Kickstarter'.

The overall campaign was a success, despite having raised only a fraction of our desired budget. Despite the lack of a screenplay, the screen idea itself was communicated quite well, using trailers, posters, social media and articles of interest. The public reaction to the film was strong and we received praise for our campaign and for the film we were trying to make. The biggest conclusion I drew from the experience was that our 'Indiegogo' page could have been crafted and launched without a screenplay having been written. As the statistics show, our funding arrived off the strength of our screen idea and not the screenplay that I wrote a year before. This suggests that our campaign doubled as a vital production document in the production of our film, one that catered to the digital consumption habits of our financiers - our implied audience. It also demonstrates how this avenue of film 
production can offer new approaches to the practice of writing for the screen and offer new agency to the screenwriter and their role in the overall production. 


\section{Conclusion}

In recent years, the independent and mainstream film industries have demonstrated a departure from the traditional techniques and practices of filmmaking. The innovation of digital technology has made for faster shooting, with film productions no longer tied to the limitations of celluloid and the film camera. Film crews have become smaller and the director is now free to embrace the fluidity of the medium. Film production has come full circle, with many production models resembling the cameraman and director systems of the early twentieth century. While such revolution is still contained largely within the independent sector of filmmaking, it has allowed for the script to find a new life outside of its traditional confines.

The first section of this article sought to establish a precedent in the past, where writers of the screen brought a background in other media of the time, such as journalism, theatre, photography and music, to their film work. I explored the evolution of screenwriting from the early days of the scenario in cinema and established that there is a relationship between the technology of the cinema of the time and the form of the screenplay. The research showed that changing media technology can affect and influence the screenplay in both writing style and structure.

In the second half of the article, I drew on contemporary examples of screenplays that attempted to break convention and employ experimental techniques involving modern multimedia technology. The examples I used draw on both Hollywood and independent productions and demonstrate the concept of the visual screenplay and how it can serve the production of a film in ways that a conventional screenplay cannot. These examples highlight how this relationship between technology and the screenplay is still evident and that the evolution of film technology is having a profound impact on the writing process also.

The example of the 'Kickstarter' campaign is an ideal case study of how digital media technology is affording the writer new opportunities and methods by which they can 
communicate the screen idea to their implied reader. In the case of these particular modes of production, the trends surrounding this technology has demanded that the role of the writer shift from wordsmith to visual artist, but the author of the screen idea nonetheless. These techniques, including image manipulation, video editing and web design are not skills that remain in the domain of industry experts, rather now they are available for all, with minimal learning curves. Munt, in his exploration of the visual script states:

[...] if, traditionally, words have been considered as expensive (literary adaptation as an industrial, commercial pursuit), then in an accelerated digital media culture (where images have never before been as cheap to produce, manipulate and distribute) a transformation is due. (2012: 60)

The ease with which these tools can and are quickly being adopted means that the crowdfunding page has in a sense become a new form of screenplay document, like the treatment or step outline, but a document that many screenwriters have yet to embrace. It mirrors the early scenarios, not just a scripting tool but a marketing one also. Sadly, the screenwriter generally plays little role in the shaping of this pivotal document.

The screen idea has multiple possibilities, even if it is written down and specified in great detail by those developing it. It is usually described in writing, in standardized forms, but it need not be. It is usually shared and developed verbally by several people, according to appropriate norms and assumptions, but again it could be developed entirely by one person on their own. (MacDonald 2013: 4)

In the academy, theorists and practitioners are arguing in favour of a revisionist approach to the role of the screenwriter, and the orthodoxy that has shaped it for so long. Millard 
demonstrates how changing technologies are now affording filmmakers the opportunity to craft their screenplay form. She uses the example of Neil Blomkamp, who when preparing District 9 (2009) used a short film, a graphic novel-style presentation, production design materials and test footage filmed on location. This gave Blomkamp a significant boost in attracting investment (Millard 2014: 39). This and the examples outlined in the chapter demonstrate that, as the convergence between technology and the page continues to manifest in film production, new and exciting approaches to the craft are revealed. The notion of a multimodal screenplay, one not bound by old traditions and industrial pressures of conformity, has greater implications for the role of the screenwriter in digital cultural studies. Shifts in the consumption of digital media, as well as the widespread adoption of social media platforms, has given rise to an array of tools that allow the writer to engage with their implied reader directly. The adoption of a wider toolkit by screenwriters to develop the screen idea is not just an expanding of the screenwriter's page, in fact, it is a revision of how we consider the page entirely. 


\section{References}

Azlant, E. (1997), 'Screenwriting for the early silent film: Forgotten pioneers, 1897-1911', Film History, 9:3, pp. 228-56.

Braff, Z. (2014), Wish I Was Here.

Dredge, S. (2014), 'Kickstarter's biggest hits: Why crowdfunding now sets the trends', The Guardian, 17 April, http://www.theguardian.com/technology/2014/apr/17/kickstartercrowdfunding-technology-film-games.

Finnegan, J. (2014), 'Still Life screenplay sample', Blog, 15 December 2015, http://screenlanguage.blogspot.co.uk/2014/02/still-life-screenplay.html.

Guerrasio, J. (2009), 'That's what friends are for', http://www.filmmakermagazine.com/archives/issues/summer2009/humpday.php\#.Vk38V0ZWUWt. Accessed 19 November 2015.

Gunning, T. (1986), 'The cinema of attractions: Early film, its spectator and the avant-garde', Wide Angle, 8:3\&4.

Kazan, E. (1954), On the Waterfront.

Loughney, P. (1997), 'From “Rip Van Winkle” to "Jesus of Nazareth": Thoughts on the origins of the American screenplay', Film History, 9:3, pp. 277-89.

Mac Coille, O. (2014), Still Life. 
MacDonald, I. W. (2013), Screenwriting Poetics and the Screen Idea, Palgrave Macmillan.

Maras, S. (2009), Screenwriting: History, Theory and Practice, Columbia University Press.

McCutcheion, W. (1904), The Suburbanite.

Millard, K. (2014), Screenwriting in a Digital Era, Palgrave Macmillan.

Moore, A. (1986), Watchmen, DC Comics.

Morse, S. (1879), The Passion Play, Theatre.

Munt, A. (2012), 'Expensive words, cheap images: "Scripting” the adapted screenplay', Journal of Screenwriting, 4:1, pp. 57-76.

Murphy, J. J. (2010), 'No room for the fun stuff: the question of the screenplay in American indie cinema', Journal of Screenwriting, 1:1, pp. 175-96.

Price, S. (2013), A History of the Screenplay, Palgrave Macmillan.

Rodriguez, R. (2004), 'Sin City Making Of', Troublemaker Studios, https://www.youtube.com/watch?v=36xJWDY4z6o.

Rodriguez, R., Miller, F. and Tarantino, Q. (2005), Sin City. 
Shelton, L. (2009), Humpday.

Stempel, T. (2000), Framework: A History of Screenwriting in the American Film, Syracuse University Press.

Thomas, R. (2014), Veronica Mars.

Varley, L. and Miller, F. (1999), 300, Gph ed., Dark Horse.

Vincent, H. C. (1898), The Passion Play of Oberammergau.

Wilder, B. (1950), Sunset Boulevard.

\section{Contributor details}

John Finnegan is a lecturer in screenwriting at Falmouth University and is a practicing screenwriter for film and other screen media. His research is both practice and critical based, which explores the relationship between screenwriting and digital technologies, as well as the remediation of the screenplay text within contemporary film production practices.

Contact:

E-mail: john.finnegan@falmouth.ac.uk 